\title{
Cytological Studies of Basidiospores of Melampsora lini
}

\author{
By R. G. KAPOORIA \\ Njala University College, University of Sierra Leone, Freetown, \\ Sierra Leone
}

(Received 9 May; revised 22 November 1972)

Since Allen's work (1933) on the cytology of Puccinia malvacearum and Savile's work ( 1939) on the nuclear structure and behaviour in species of the Uredinales, much information has appeared on the cytological details of many fungi (McGinnis, 1953, I956; Dowding \& Weijer, 1960; Pavgi, Cooper \& Dickson, 1960; Ward \& Ciurysek, 1962; Weijer, Kopmans \& Weijer, I963; Kapooria, I968; Robinow \& Caten, 1969). In recent years concepts of vegetative nuclear division in fungi have been modified by reports of occurrence of chromosomes on a linear filament (Dowding \& Weijer, I960; Heale, Gafoor \& Rajasingham, I968; Giatong \& Frederiksen, 1969). In the present work basidiospores of Melampsora lini (Ehrenb) Lév, the fungus causing rust disease of Linum usitatissimum L. have been studied for their cytological behaviour during somatic division.

\section{METHODS}

Infected stems of linseed-bearing telial sori of Melampsora lini were collected from plants growing in an experimental plot at Wieringerwerf (Holland). Pieces of infected stems were washed for a few hours in running tap water until the sori became soaked. The sori were then scraped with a scalpel to remove the protective layers of cuticle and epidermis so that the subepidermal teleutospores could germinate. The stem surface bearing telial sori was peeled and the peels applied to a thin layer of moist cotton held in the upper lid of a Petri dish. After approximately two weeks at $16{ }^{\circ} \mathrm{C}( \pm \mathrm{I})$ the teleutospores germinated and shed basidiospores on slides placed underneath. Slides bearing basidiospores in various stages of nuclear division were fixed in aceto-alcohol ( I:3) for I h. Samples were obtained at hourly intervals to observe the behaviour of nuclei during time. The slides with basidiospores were stained by flooding with $0.5 \%$ aceto-carmine. Prepared slides were immediately examined and those showing illustrative stages were photographed using a Leitz Laborlux microscope fitted with a Leica camera.

\section{RESULTS AND DISCUSSION}

Freshly discharged basidiospores are uninucleate. The nucleus at this stage is globular (Fig. I $a$ ). Prior to division there is a slight enlargement of the nucleus (Fig. $\mathrm{I} b$ ) and the chromatin network begins to appear (Fig. I $c, d$ ). During the opening of the chromatin a long, continuous, filamentous structure becomes prominent (Fig. I $e, f$ ). The chromatin filament begins to shorten and, during this process, it passes through looped (Fig. I $g, h$ ) and zigzag (Fig. $\mathrm{I} i$ ) configurations. During these changes (Fig. $1 g-i$ ) chromosomes are not distinctly seen but dense chromatin bodies appear on the chromatin filament. In Fig. I $(h, i)$ five such bodies can be counted on each filament. These chromatin bodies later separate (Fig. I $j$ ) and chromosomes take on a more distinct appearance (Fig. I $k$ ). The metaphase plate has been generally found near the centre of the basidiospore (Fig. I $l, m$ ). Careful examination of the metaphasic chromosomes in Fig. I $(l, m)$ reveal five to six chromosomes of approximately 0.7 to $0.8 \mu \mathrm{m}$ length. The chromosomes divide and the daughter chromatids 

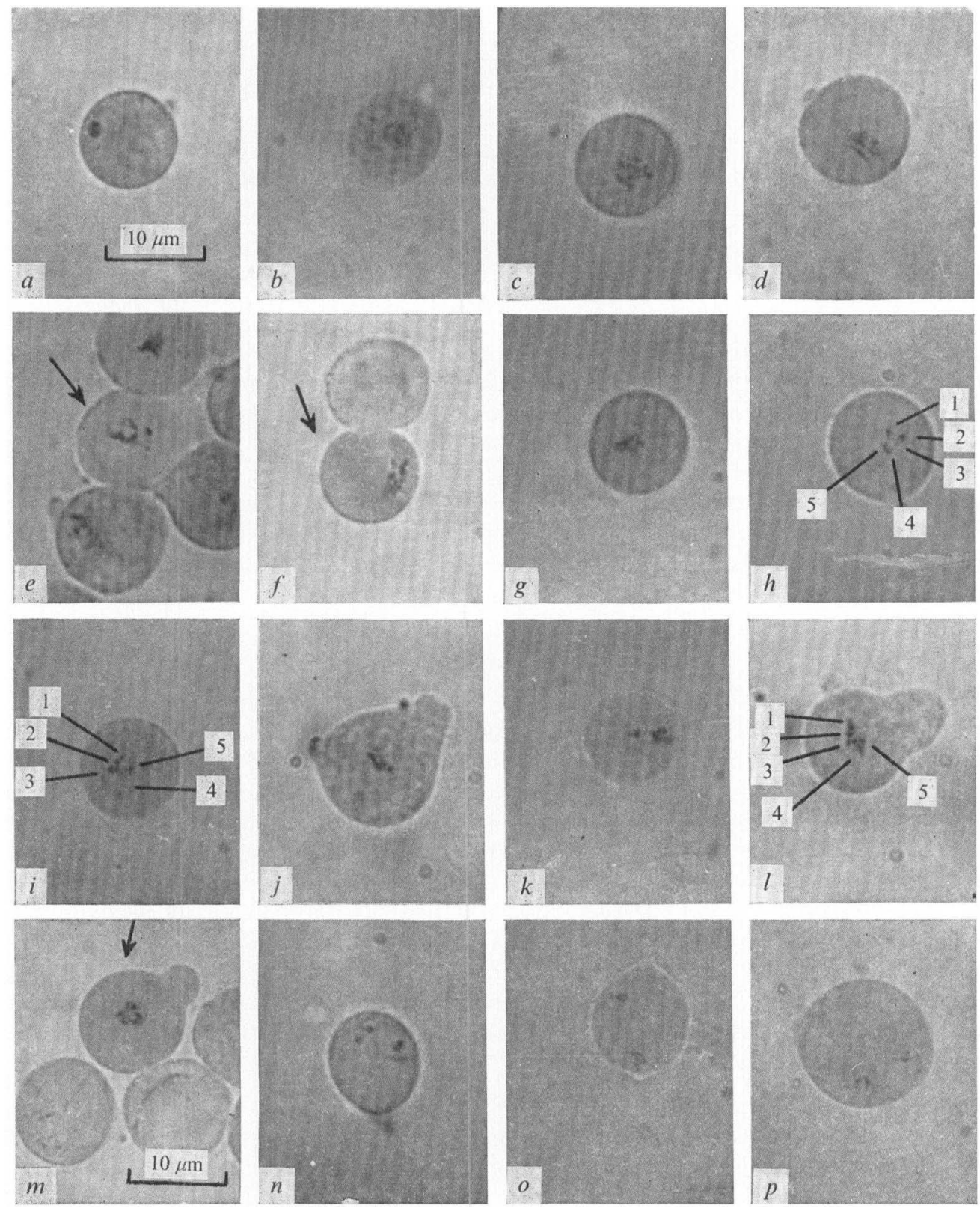

Fig. 1. Stages in the nuclear division in basidiospores of Melampsora lini. (a) Resting nucleus showing a globular appearance; $(b)$ nucleus showing increased size prior to division (nucleus enlargement stage); $(c),(d)$ chromatin reticulum becoming distinct; $(e),(f)$ chromatin filament in the process of opening; $(g)$ chromatin filament showing a looped configuration; $(h),(i)$ chromatin filament showing looped and zigzag configurations and showing five dense bodies; $(j),(k)$ chromatin filament in the process of breaking; $(l),(m)$ metaphasic plates showing five and six chromosomes respectively; $(n)$ daughter chromatids migrating in opposite directions in zigzag configurations; $(o)$ daughter chromatids at their respective poles; $(p)$ chromatids arranged end to end in a ring-like configuration. 
formed migrate in opposite directions to reach their respective poles (Fig. I $n, o$ ). The daughter nuclei reconstitute at the termination of nuclear division.

Chromatin bodies have been interpreted as chromosomes by Girbardt (1964), Weijer \& Weisberg (1966), Laane (1967), Heale et al. (1968) and Giatong \& Frederiksen (1969). Metaphasic figures showed either five or six chromosomes.

The existence of classical and atypical mitoses in fungi is now fairly well established. Classical mitosis in fungi has been demonstrated by McGinnis (1953, 1956), Somers, Wagner \& Hsu (I960), Ward \& Ciurysek (I96I, I962), Lu (I962), and Hartman (I964). Atypical mitosis has been demonstrated by Robinow (1957, 1962), Weijer, Kopmans \& Weijer (1965), and Heale et al. (1968). The existence of a long chromatin thread either in a ring-like or a filamentous configuration carrying dense bodies has been reported by Girbardt (1964), Robinow \& Caten (1969), and Giatong \& Frederiksen (1969). Melampsora lini is an organism with an atypical mitosis.

I express my gratitude to Ir. R. E. Labruyère, Mycologist, and to Ir. E. Ubels, Head of the Department of Plant Disease Resistance, Institute of Phytopathological Research, Wageningen, The Netherlands for help in microphotography and for useful suggestions respectively.

\section{REFERENCES}

Allen, R. F. (1933). A cytological study of the teliospores, promycelia, and sporidia in Puccinia malvacearum. Phytopathology 23, 572-586.

Dowding, E. S. \& WeiJer, J. (1960). Mitosis in Neurospora. Nature, London 188, 338-339.

Giatong, P. \& Frederiksen, R. A. (I969). Pathogenic variability of Pyricularia oryzae. Phytopathology 59, I I 52-I I 57.

GirbardT, M. (1964). Demonstration of electron micrographs. 10th International Botanical Congress at Edinburgh.

Hartman, G. C. (1964). Nuclear division in Alternaria tenuis. American Journal of Botany 5I, 209-2 I 2.

Heale, J. B., Gafoor, A. \& Rajasingham, K. C. (I968). Nuclear division in conidia and hyphae of Verticillium albo-atrum. Canadian Journal of Genetics and Cytology 1o, $32 \mathrm{I}-340$.

Kapooria, R. G. (I968). Cytological studies of the germinating teliospores and basidiospores of Puccinia penniseti. Netherlands Journal of Plant Pathology 74, 2-7.

LaAne, M. M. (1967). The nuclear division in Penicillium expansum. Canadian Journal of Genetics and Cytology 9, 342-351.

Lu, B. C. (1962). A new fixative and improved propiocarmine squash technique for staining fungus nuclei. Canadian Journal of Botany 40, 843-847.

McGinnis, R. C. (I953). Cytological studies of chromosomes of rust fungi. I. The mitotic chromosomes of Puccinia graminis. Canadian Journal of Botany 31, 522-526.

MCGinnis, R. C. (1956). Cytological studies of rust fungi. III. The relationship of chromosome number to sexuality in Puccinia. Journal of Heredity 47, 255-259.

Pavgi, M. S., Cooper, D. C. \& Dickson, J. G. (1960). Cytology of Puccinia sorghi. Mycologia 52, 608-620.

RoBinow, C. F. (1957). The structure and behaviour of the nuclei in spores and growing hyphae of Mucorales. I. Mucor hiemalis and Mucor fragilis. Canadian Journal of Microbiology 3, 923-926.

Robinow, C. F. (1962). Some observations on the mode of division of somatic nuclei of Mucor hiemalis and Allomyces. Archiv für Mikrobiologie 42, 369-377.

Robinow, C. F. \& CATEn, C. E. (1969). Mitosis in Aspergillus nidulans. Journal of Cell Science 5, 403-431.

SAVILE, D. B. O. (1939). Nuclear structure and behaviour in species of Uredinales. American Journal of Botany 26, 585-609.

Somers, C. E., Wagner, R. P. \& Hsu, T. E. (1960). Mitosis in vegetative nuclei of Neurospora crassa. Genetics 45, 80I-8IO.

WARD, E. W. B. \& CIURYSEK, K. W. (1961). Somatic mitosis in a basidiomycete. Canadian Journal of Botany 39, 1497-1503.

WARD, E. W. B. \& CiURYSEK, K. W. (1962). Somatic mitosis in Neurospora crassa. American Journal of Botany 49, 393-399. 
Weijer, J., Kopmans, A. \& Weijer, D. L. (1963). Karyokinesis in vivo of the migrating somatic nucleus of Neurospora and Gelasinospora species. Transactions of New York Academy of Sciences 25, 846-854.

Weijer, J., Kopmans, A. \& WeiJer, D. L. (1965). Karyokinesis on somatic nuclei of Neurospora crassa. Canadian Journal of Genetics and Cytology 7, 140-163.

WeiJer, J. \& WeisBerG, S. H. (1966). Karyokinesis of the somatic nucleus of Aspergillus nidulans. I. Juvenile chromosome cycle (Feulgen staining). Canadian Journal of Genetics and Cytology 8, 36I-374. 